\title{
Self-expanding Metallic Stent Placement in Malignant Terminal lleal Stricture
}

\author{
Kailash Raj Makhejani1, Muhammad Mansoor UI Haq², Jawaid Iqbal33, Naila Zahid4 \\ ${ }_{1}^{1}$ Department of Gastroenterology, Toronto General Hospital/UHN, Toronto, ON, Canada \\ Department of Gastroenterology \& Hepatology2 / Radiology3 / Oncology4, Liaquat National Hospital, Karachi, Pakistan
}

\begin{abstract}
Malignancies of gastro-intestinal tract cause stricture formation that leads to intestinal obstruction. In such cases, either surgery or placement of self-expanding metallic stents (SEMS) are options of palliation. For left sided colorectal obstruction, SEMS have been widely used and reported. Luminal stenting is not always an easy task to perform because of altered anatomy of the surrounding structures, specially in the right side of colon and terminal ileum. SEMS placement, particularly in the ileocecal region, is technically difficult. Few studies on SEMS deployment in right sided colon have been reported till now. We report a case of metastatic signet ring cell carcinoma of rectosigmoid junction with malignant terminal ileal stricture palliation done with placement of SEMS.
\end{abstract}

Key Words: Colorectal cancer, Luminal stenting, Terminal ileum stricture, Malignant stricture.

How to cite this article: Makhejani KR, Haq MM, lqbal J, Zahid N. Self-expanding metallic stent placement in malignant terminal ileal stricture. J Coll Physicians Surg Pak 2019; 29 (Supplement 2):S89-S91.

\section{INTRODUCTION}

Malignancies of gastrointestinal tract cause stricture formation that leads to intestinal obstruction. Most of these cases are so advanced that curative management becomes impossible. In these cases, either surgery or placement of self-expanding metallic stents (SEMS) are options of palliation. Luminal stenting has been widely used for obstruction in left side of colon. ${ }^{1}$ Metallic stenting is not always an easy task to perform because of altered anatomy of the surrounding structures, especially in the right side of colon and terminal ileum. Endoscopic access to ileocecal lesions also becomes difficult due to long distance from anal canal and tortuosity of bowel. Few studies on SEMS deployment in right sided colon have been reported till now. ${ }^{1-3}$ We report a case of carcinoma of sigmoid colon that did not respond to neo-adjuvant therapy and presented with obstruction at terminal ileum due to metastasis.

\section{CASE REPORT}

A 28-year lady, admitted to Liaquat National Hospital, with diagnosis of metastatic signet ring cell carcinoma of recto-sigmid junction having peritoneal carcinomatosis, status post diversion colostomy, was on chemotherapy with 5 flourouracil and xelox. She was referred to us for

Correspondence to: Dr. Kailash Raj Makhejani, Department of Gastroenterology, Toronto General Hospital/UHN, Toronto, ON, Canada.

E-mail:drkrm2003@gmail.com

Received: February 26, 2019; Revised: June 17, 2019;

Accepted: June 17, 2019 generalised abdominal pain and distension with nausea, vomiting, constipation. She was vitally stable but tachycardic. On examination, abdomen was distended, and diffusely tender. Rebound tenderness was not appreciated but shifting dullness was positive. While auscultating the abdomen, bowel sounds were hypoactive. Her blood work showed mild normocytic anemia and thrombocytopenia, rest of the blood tests were within normal ranges. An abdominal computed tomography (CT) scan discovered complete obstruction due to stricture at terminal ileum and dilated proximal small intestinal loops (Figure 1,2). After discussing with surgical team, it was concluded that surgery was not possible option as disease was already in an advanced stage. So, her colonoscopy and enteral stenting (SEMS) of the terminal ileal stricture was scheduled and executed as described below. Special consideration was given to use minimum possible air insufflation during procedure. Following deployment of stent, her complaints did not subside even after 72 hours post-procedure and abdominal X-ray displayed incomplete opening of metallic stent. So, we planned and performed dilatation of metallic stent by controlled radial expansion (CRE) balloon during colonoscopy this time. Finally, her bowels moved, she started tolerating liquids and soft diet. She remained asymptomatic for next 30 days following the procedure.

The procedures of SEMS deployment is briefly described as under:

After obtaining informed consent, intravenous $5 \mathrm{mg}$ of midazolam hydrochloride and $2 \mathrm{mg}$ of nalbuphine diluted in normal saline were used for the purpose of conscious 


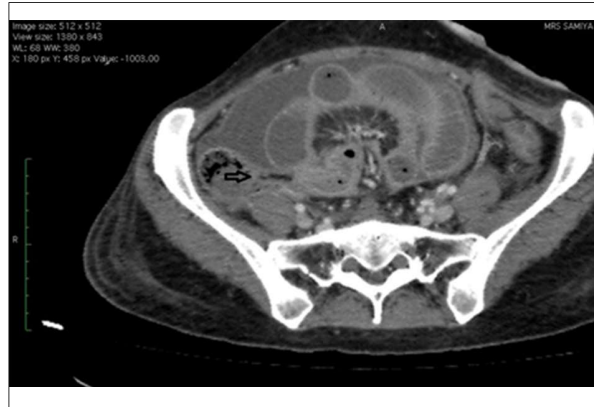

Figure 1: CT scan abdomen axial section image. Arrow points out terminal ileal stricture.

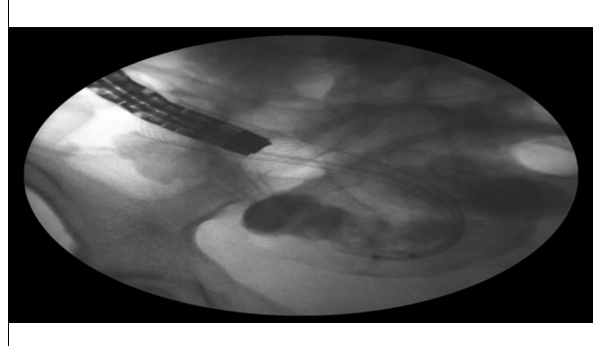

Figure 4: Flouroscopic view of terminal ileal SelfExpanding Metallic Stent (SEMS).

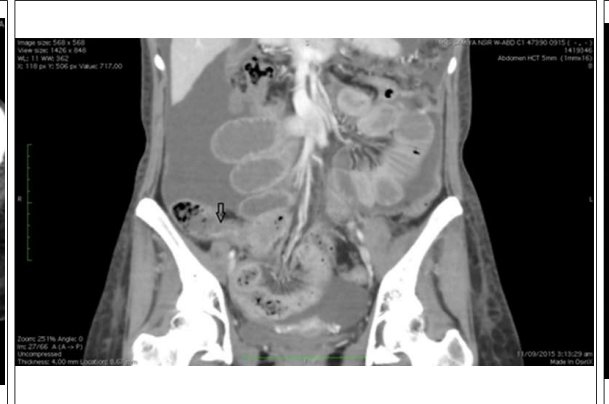

Figure 2: CT scan abdomen coronal section image. Arrow shows terminal ileal stricture.

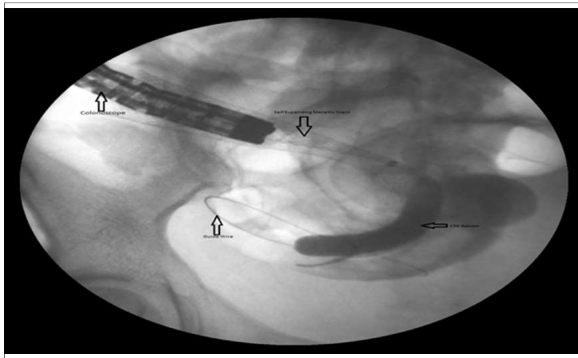

Figure 5: Flouroscopic view of terminal ileal SelfExpanding Metallic Stent (SEMS) with CRE Balloon.

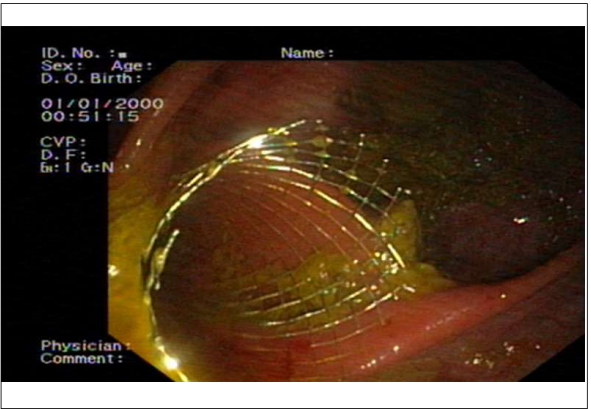

Figure 3: Endoscopic view of terminal ileal SelfExpanding Metallic Stent (SEMS).

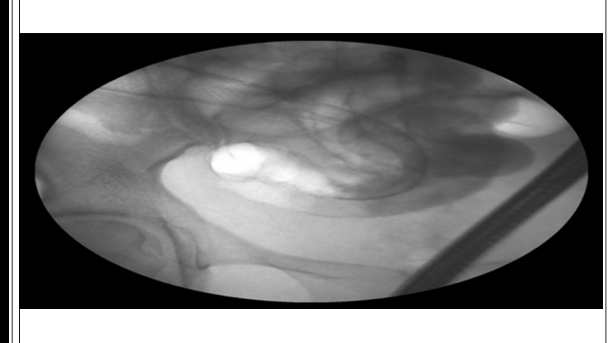

Figure 6: Flouroscopic view of terminal ileal SelfExpanding Metallic Stent (SEMS) after CRE Balloon dilatation. sedation for the procedure. She was kept in supine position. Video-colonoscope (Olympus CF 160 Olympus America Inc., Melville, New York) was inserted through colostomy stoma opening and forwarded to terminal ileum. A 0.035 guidewire preloaded into a biliary balloon (15 mm, Wilson-Cook, USA) was passed across the ileocecal valve and ileal stricture. For confirming the site and size of stricture, water-soluble radiographic contrast was introduced. Finally, balloon was retrieved while keeping the guide wire beyond the stricture and an uncovered SEMS $(22 \times 90 \mathrm{~mm}$, Boston Scientific, Natick, Massachusetts, USA) was transported over the guidewire and across the working channel of the endoscope. Stent was positioned under endoscopic and fluoroscopic assistance (Figure 3,4); proximal end being in the ileum across the stricture and the distal end at the ileocecal valve. The stent at the site of stricture was opened only slightly for initial 72 hours and patient's complaints of vomiting and abdominal pain did not subside. Therefore, we performed CRE balloon (18-20mm, Boston Scientific, Natick, Massachusetts, USA) dilatation (Figure 5,6).

\section{DISCUSSION}

Currently available stents for malignant and benign alimentary tract conditions include SEMS and selfexpanding plastic stent (SEPS). ${ }^{1}$ Palliation for malignant gastro-intestinal and biliary obstruction with SEMS deployment shows long-term outcome of $70 \%$ stent patency until death; and most re-obstructions could be addressed endoscopically. ${ }^{2}$ The efficacy of SEMS placement for Crohn's disease-related benign intestinal strictures has also been reported in the literature. ${ }^{3}$ To the best of our knowledge; uptill now, few cases of malignant terminal ileal stricture with metallic stent placement have been reported.1,4-7 SEMS has also been used as a bridge to surgey with good outcomes. 8-10 SEMS can be either covered or uncovered, major drawback of each of these being relocation, migration and tumor ingrowth, respectively. By fleeting enteral uncovered stent through the therapeutic working channel $(\geq 4.2$ $\mathrm{mm}$ ) of endoscope allows lesions as far proximally or distally as those that are within reach to be alleviated. 6 Though, luminal stenting is a technically innocuous procedure, but imaginable hitches and complications include bleeding, perforation, fistula formation, stent migration and/or malposition and stent occlusion.

Without any doubt, this is a technically demanding intervention. Hurdles that might be faced include difficulty in passing a guidewire across the stricture and disappointment in reaching the site of obstruction due to stubborn and un-maneuverable colonic angulations. In such cases, duration of procedure may also increase. All in all, in terminally ill cases, the enteral stenting is highly efficacious both technically and clinically in alleviating malignant impediment, thus averting necessity of surgical procedure. As a whole, stenting is a timeconsuming procedure but helps sufferer a lot and CRE balloon dilatation of incompletely opened stent is another easy and safe option which may help in alleviation of obstructive symptoms as in our case. So, this technique can be considered in such difficult cases for alleviation of symptoms in expert hands. 


\section{PATIENT'S CONSENT:}

Informed consent was obtained from the patient.

\section{CONFLICT OF INTEREST:}

Authors declared no conflict of interest.

\section{AUTHORS' CONTRIBUTION:}

KRM: Designed and authored the manuscript. MMUH: Provided concept of manuscript and proofread the final version before submission and performed procedure. $\mathrm{JI}, \mathrm{NZ}$ : Contributed in analysis, acquisition, revision and final proof.

\section{REFERENCES}

1. Ishii $\mathrm{T}$, Minaga $\mathrm{K}$, Ogawa $\mathrm{S}$, Ikenouchi M, Yoshikawa T, Akamatsu T, et al. Effectiveness and safety of metallic stent for ileocecal obstructive colon cancer: A report of 4 cases. Endosc Int Open. 2017; 5:E834-8.

2. ASGE Technology Committee. Enteral Stents. Gastrointest Endosc 2011;74:455-64.

3. Larssen L, Medhus AW, Körner H, Glomsaker T, Søberg T, Gleditsch $\mathrm{D}$, et al. Long-term outcome of palliative treatment with self-expanding metal stents for malignant obstructions of the GI tract. Scand J Gastroenterol 2012; 47:1505-14.
4. Loras C, Pérez-Roldan F, Gornals JB, Barrio J, Igea F, González-Huix F, et al. Endoscopic treatment with selfexpanding metal stents for Crohn's disease strictures. Aliment Pharmacol Ther 2012; 36:833-9.

5. Chahal P, Baron TH. Endoscopic palliation of malignant terminal ileum stricture using a metallic enteral endoprosthesis. VHJOE 2006 Vol5, Issue 1. (http://www.vhjoe.org/ Volume5Issue1/5-1-2.htm).

6. Suzuki S, Kusano C, Yoshizawa N, Nakamura M, Hirasawa T, Gotoda $\mathrm{T}$, et al. Long-term release of a malignant ileal obstruction by placement of a colorectal self-expandable metal stent. Clin J Gastroenterol 2013; 6:202-6.

7. Simmons DT, Baron TH. Endoluminal palliation. Gastrointest Endosc Clin N Am 2005; 15:467-84.

8. SaidaY, EnomotoT, Takabayashi K. Outcome of 141 cases of self-expandable metallic stent placements for malignant and benign colorectal stricture in a single center. Surg Endosc 2011; 25:1748-52.

9. Sasaki T, Yoshida S, Isayama H. Metallic stent placement for malignant enteral obstruction based on the type of enteral stent. Gastroenterol Endosc 2015; 57:172-84.

10. Ji WB, Kwak JM, Kang DW, Kwak HD, Um JW, Lee SI, et al. Clinical benefits and oncologic equivalence of self-expandable metallic stent insertion for right-sided malignant colonic obstruction. Surg Endosc 2017; 31:153-8. ....占.... 